\title{
From Design to Implementation to Practice a Learning by Teaching System: Betty's Brain
}

\author{
Gautam Biswas $^{1} \cdot$ James R. Segedy $^{1}$. \\ Kritya Bunchongchit ${ }^{2}$
}

Published online: 2 July 2015

(C) International Artificial Intelligence in Education Society 2015

\begin{abstract}
This paper presents an overview of 10 years of research with the Betty's Brain computer-based learning environment. We discuss the theoretical basis for Betty's Brain and the learning-by-teaching paradigm. We also highlight our key research findings, and discuss how these findings have shaped subsequent research. Throughout the course of this research, our goal has been to help students become effective and independent science learners. In general, our results have demonstrated that the learning by teaching paradigm implemented as a computer based learning environment (specifically the Betty's Brain system) provides a social framework that engages students and helps them learn. However, students also face difficulties when going about the complex tasks of learning, constructing, and analyzing their learned science models. We have developed approaches for identifying and supporting students who have difficulties in the environment, and we are actively working toward adding more adaptive scaffolding functionality to support student learning.
\end{abstract}

Keywords Open-ended learning environments $\cdot$ Learning by teaching $\cdot$ Pedagogical agents $\cdot$ Adaptive scaffolding $\cdot$ Coherence analysis $\cdot$ Characterizing student behaviors

\section{Introduction}

Betty's Brain was designed to make science learning an active, constructive, and engaging process for students (Brophy et al. 1999; Biswas et al. 2001). A primary innovation in our computer based learning environment was to leverage the learning by teaching paradigm (Bargh and Schul 1980; Benware and Deci 1984; Biswas et al.

Gautam Biswas

gautam.biswas@Vanderbilt.Edu

1 Vanderbilt University, Nashville, TN, USA

2 Mahidol University, Bangkok, Thailand 
2005) to get students to research and construct models of science phenomena in the guise of teaching a virtual agent named Betty. Students actively engaged with Betty during the learning process by asking her questions and getting her to take quizzes that were provided by a mentor agent named Mr. Davis. When asked to answer questions or to take a quiz, Betty used simplified qualitative reasoning mechanisms to chain together a sequence of links and generate answers like, "If deforestation increases, the amount of heat trapped by the earth will increase" (Leelawong and Biswas 2008). Betty's performance on the quizzes (i.e., an indication of which of the quiz answers were correct and incorrect) provided the feedback that students needed to check their map and come up with strategies for identifying and correcting errors and omissions in their maps. When asked, Betty could provide explanations for her derived answers, and this helped students identify and analyze the individual links that she used to generate her answers. Betty also provided motivational feedback by expressing happiness when her scores on the quiz improved, and she expressed disappointment when her quiz scores did not improve. Additional feedback was provided by the mentor agent in the form of learning strategies that students could employ when they were not performing well.

This paper presents an overview and a reflection of the trajectory of our research with Betty's Brain, from the work that led to our "classic" paper (Leelawong and Biswas 2008) to our more recent work in understanding how students tackle the Betty's Brain learning task, the difficulties they face, and approaches we have been developing to support students as they learn with Betty's Brain. Results of studies we conducted in middle school classrooms over the years have demonstrated that the learning by teaching paradigm implemented as a computer based learning environment provides a social framework that engages students and helps them learn. However, students also face difficulties when going about the complex tasks of learning, constructing, and analyzing their learned structures that are represented as causal maps. A deeper analysis of these difficulties has led us to refocus our research on effective ways of scaffolding students in open-ended learning environments like Betty's Brain. The goal is to engage students with differing capabilities and prior knowledge in the challenging task while also providing additional support to help them succeed in their learning and problem solving activities.

\section{The Original Betty's Brain Learning Environment}

Our initial design and development of the Betty's Brain system was guided by the social-constructivist theories of learning (e.g., Palincsar 1998), reciprocal teaching (e.g., Palincsar and Brown 1984), and peer-assisted tutoring (e.g., Willis and Crowder 1974; Cohen et al. 1982). Researchers (e.g., Bargh and Schul 1980; Benware and Deci 1984) have shown that people learn more when their grade depends on their pupils' performance instead of their own. However, unlike previous learning by teaching systems (e.g., Chan and Chou 1997; Michie et al. 1989; Obayashi et al. 2000; Palthepu et al. 1991) our goal was not to make learning agents that, for instance, learn by example or by observing user behaviors. Instead, our design focused on creating an agent that students must explicitly teach. In response, the agent reasons with and can answer questions only on what she was taught, nothing more and nothing less.

Therefore, the learning by teaching paradigm adopted in Betty's Brain explicitly asks students to read about a science topic and develop an understanding of it by creating a 
shared representation (i.e., a visual causal map). This facilitates learning about science knowledge and applying it to problem solving processes (Biswas et al. 2005b; Leelawong and Biswas 2008). In addition, the shared representation also promotes a shared responsibility where the student teaches Betty; and Betty uses that knowledge to answer questions. Students may not know how to reason with the map, but they can (and do) learn by observing Betty (Leelawong and Biswas 2008). Ideas of shared responsibility were implemented in early work on reciprocal teaching (Palincsar and Brown 1984), socially-mediated cognition (Goos 1994), and collaborative learning (Dillenbourg 1999). The combination of shared representation and shared responsibility helps distribute the cognitive work (Arias et al. 2000) and at the same time provides a visual formal language for building models of science phenomena in ways that promote learning (Scardamalia and Bereiter 1989; Vygotsky 1978).

In our early work on Betty's Brain, we built up on the combined ideas of shared representation and shared responsibility to design a comprehensive learning by teaching system that adopted the following design principles (Biswas et al. 2005a, b): (i) teaching through visual representations that help organize the science content and reasoning structures; (ii) developing an agent that performs independently and provides feedback on how well it has been taught; and (iii) building on familiar teaching interactions (preparing to teach, asking questions, and monitoring and reflecting on Betty's performance) to organize student activity. The novelty in this approach was that students not only got to organize their understanding in a formal representation, but they also learned to reason with the causal map and answer questions. We believed that the ability to see Betty's approach to reasoning would support students' ability to monitor and regulate their understanding of the domain knowledge they were teaching.

The paradigm builds on research from educational psychology that has identified a tutor learning effect in people from diverse backgrounds, and across subject matter domains (Roscoe and Chi 2007). The findings state that people generally learn as a consequence of teaching others, and this effect has been observed in multiple tutoring formats. In effect, the learning by teaching paradigm leverages the power of an immersive narrative (learning by teaching) to motivate students. This was demonstrated both in our earlier work (Biswas et al. 2005a, b; Tan and Biswas 2006; Tan et al. 2006; Wagster et al. 2007) and in additional studies by our colleagues at Stanford University who have identified a protégé effect: students who constructed causal maps for the purposes of teaching Betty were more motivated and exerted more effort than students who constructed causal maps for themselves (Chase et al. 2009). Students who taught also associated social characteristics with their agents by attributing mental states and responsibility to them. The authors mused: "Perhaps having a TA invokes a sense of responsibility that motivates learning, provides an environment in which knowledge can be improved through revision, and protects students' egos from the psychological ramifications of failure" (p. 334).

The interface to the original Betty's Brain system is shown in Fig. 1. The system was configured to teach middle school students about science topics such as river ecosystems and climate change. The system provided three primary functions: (1) teach Betty using a causal map; (2) ask Betty questions; and (3) quiz Betty. Students could seek help from Mr. Davis, the mentor agent, at any time by clicking on an "Ask Mr. Davis" button. The help Mr. Davis provided included answers to general questions like "How do I build a concept map?", "How do I search for specific information in the resources?", and "How does Betty answer a question using the concept map?" After 
Betty took a quiz, Mr. Davis graded it, and, if asked, provided specific feedback on how to find errors and make corrections to the map.

To engage students in the learning by teaching narrative, we designed Betty and $\mathrm{Mr}$. Davis to interact conversationally with the students. In addition to engaging with the student socially (e.g., "Thanks for teaching me about climate change!"), these interactions were also designed to support students in developing and employing metacognitive strategies for teaching Betty (Schwartz et al. 2007; Tan and Biswas 2006; Wagster et al. 2007). These strategies included: (1) reading the resources carefully to find new causal links; (2) re-reading resources in a targeted manner to correct erroneous links; and (3) when necessary, probing further by posing queries and checking explanations to find incorrect links. Additional details of the Betty's Brain system and earlier experiments conducted with this system are summarized in (Biswas et al. 2005a, b; Leelawong and Biswas 2008).

\section{Transition into the Classroom}

Our early studies with Betty's Brain were conducted as pull-out studies; researchers worked with small groups of students and were available to offer guidance and support when students were unsure of how to proceed. Overall, these studies demonstrated the

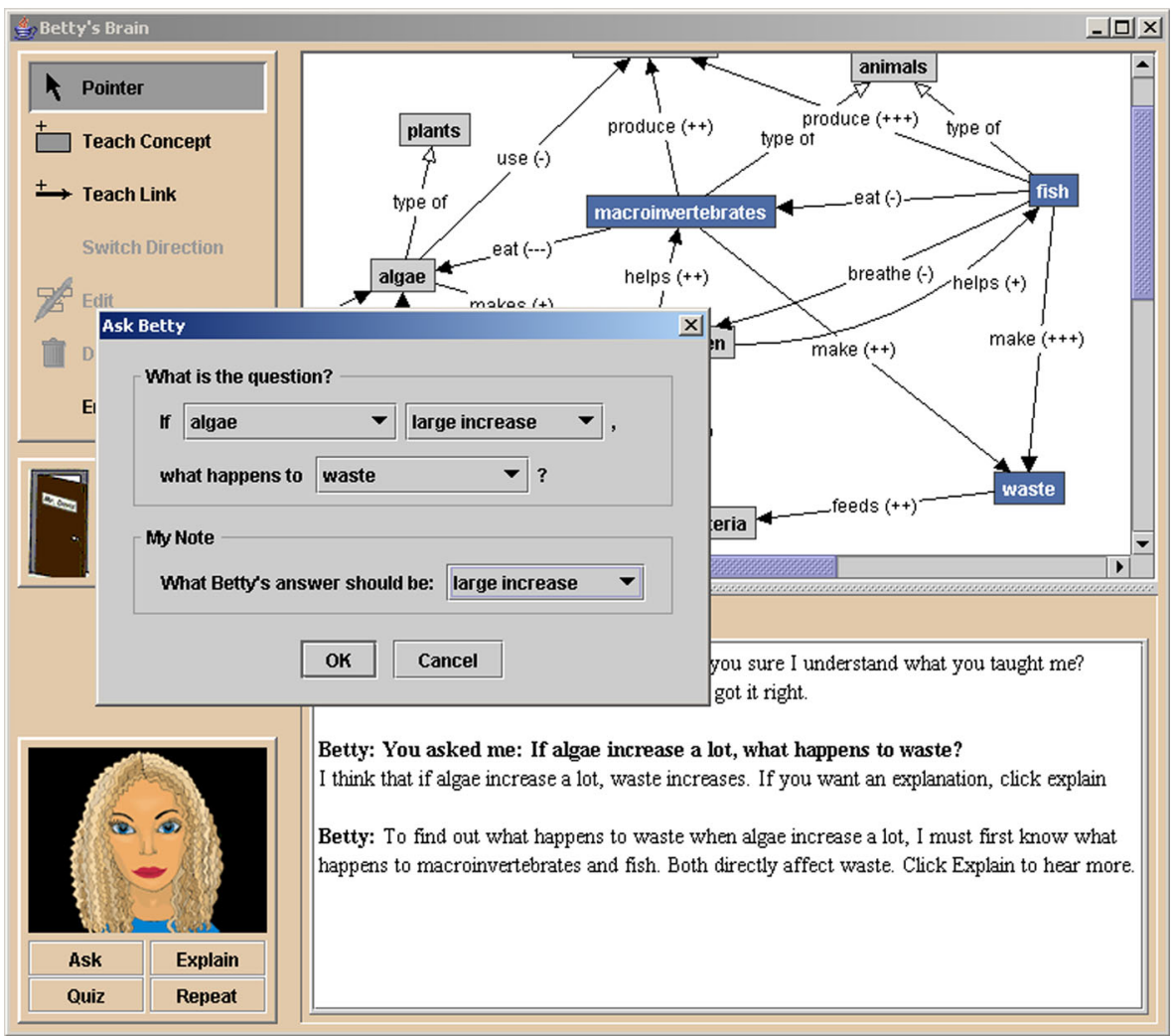

Fig. 1 Original Betty's Brain system showing a causal map and the query window 
promise of the system and its theoretical framing; we found that the learning by teaching approach led to better pre-post learning gains for students. Further, students who received feedback on metacognitive processes demonstrated more effective learning behaviors (Biswas et al. 2005a, b; Leelawong and Biswas 2008). They used more systematic methods for checking the correctness of their maps and made better use of the system's interface features.

Following these successes, we began focusing on integrating Betty's Brain into middle school science classrooms (Wagster et al. 2008). The most consequential change resulting from this shift was the fact that students needed to work more independently on teaching Betty; we did not have enough researchers to provide the level of support we could in the pull-out studies. It was during these classroom evaluations that we noticed the wide variation in students' learning and performance with Betty's Brain (Kinnebrew et al. 2013; Segedy et al. 2014; Segedy et al. 2012a). A number of students struggled with understanding how to use the system productively; they struggled to teach Betty the correct links. Further probing and analysis of these students, including their log files and conversations with researchers, showed that many of them were unsure of how to identify causal relations as they read the text resources, translate those relations into the causal modeling language provided by the system, and use Betty's quiz results to monitor the quality of the causal map. Overall, this led to perpetually low quiz scores, frustration, and disengagement for a significant proportion of students. For example, one study of 40 students (reported in Kinnebrew et al. 2013) found that 18 of the students made very little progress in teaching Betty the correct material. Of the remaining 22 students, 16 taught Betty a correct (or nearly correct) map, and 6 students made meaningful progress in their teaching. Thus, while some students struggled considerably, just as many students showed good understanding and succeeded at the task.

We found this dichotomy intriguing, and much of our subsequent analyses went into understanding and contrasting how these more and less successful students used the system. The resulting analyses, which utilized hidden Markov models, differential sequence mining, and statistical analyses (Biswas et al. 2010; Kinnebrew and Biswas 2012; Kinnebrew et al. 2013; Segedy et al. 2012a, b; 2014) were revealing. More successful students: (1) exhibited significantly higher science learning gains; (2) were more accurate in their causal map edits; and (3) performed actions that were more often related to their recent previous actions, suggesting that they were more focused and less random in their activities. This was further supported by the fact that more successful students were more likely to productively combine map editing, reading, and quizzing behaviors when compared to less successful students.

Repeated classroom evaluations of Betty's Brain conducted between 2009 and 2011 consistently showed this performance dichotomy. The dichotomy persisted even as we designed new feedback for students to help them overcome their difficulties. This feedback, channeled through Mr. Davis, was designed to provide metacognitive strategy suggestions by telling students how they might be able to improve Betty's quiz scores. For example, Mr. Davis would encourage students to read the resources about the concepts that Betty used to generate her incorrect answers in order to find mistakes in the links connecting these concepts. These suggestions were embedded in contextualized conversations (Segedy et al. 2013a, b). Mr. Davis contextualized his suggestions in Betty's current map, her most recent quiz results, and the student's recent activities. 
Moreover, he delivered the feedback through conversations that were mixed-initiative, back-and-forth dialogues between the student and the agent implemented as conversation trees (Adams 2010).

As we continued to study students' learning behaviors, particularly the behaviors of students who struggled to succeed in Betty's Brain, we collected careful observations of how they used the system. Surprisingly, these students did not seem to pay attention to and try to implement suggestions and advice provided by Mr. Davis and Betty. In one study, we analyzed video data from students using Betty's Brain and found that $77 \%$ of the feedback delivered by Betty and Mr. Davis were ignored by students (Segedy et al. $2012 b$ ). These observations led us to realize that students had difficulties in understanding and interpreting the importance of the strategy suggestions provided by the mentor agent. Additional observations seemed to imply that this could be attributed to underdeveloped cognitive skills that are essential to being successful in the system. For example, many students, when presented with a paragraph of text, struggled to identify the causal relationship described therein.

This prompted us to analyze the Betty's Brain tasks in more detail; what pre-requisite skills might students not possess, and how can we help students develop those skills? In answering these questions, we developed a task model that captures these tasks and their dependency relationships (Segedy et al. 2014; Kinnebrew et al. 2014). Using this model as a framework, we re-conceptualized and redesigned Betty's Brain. The new system, presented in the next section, has allowed us to study students' approaches to learning with Betty's Brain in greater detail than was previously possible. It also features new approaches to scaffolding students' learning in Betty's Brain.

\section{The Re-Designed Betty's Brain: Focus on Open-Ended Learning Environments}

In redesigning Betty's Brain, we realized that our system shares several characteristics with other computer-based learning environments developed by the research community. Students are presented with a modeling task (building a causal map), provided with resources for learning about the science knowledge needed to build the model, and given tools for building and testing their causal maps. In other words, Betty's Brain fits the definition of an open-ended learning environment (OELE; Clarebout and Elen 2008; Land et al. 2012; Land 2000). OELEs are learner centered; they provide a learning context and a set of tools for exploring, hypothesizing, and building solutions to authentic and complex problems, and are typically designed "to support thinkingintensive interactions with limited external direction" (Land 2000; p. 62). As such, these environments are well-suited to prepare students for future learning (Bransford and Schwartz 1999) by developing their abilities to independently make choices when solving open-ended problems.

Under this conceptualization, students learning with Betty's Brain must solve the open-ended problem of teaching Betty the correct causal model by gaining an understanding of the science topic, translating that understanding into a causal model, and using the results of Betty's quizzes as feedback to help guide subsequent learning, teaching, and model development activities. Our conceptual understanding of these tasks is shown as a hierarchical task model in Fig. 2 (Segedy et al. 2014; Kinnebrew 
et al. 2014). This model characterizes the tasks that are important for achieving success in OELEs generally and Betty's Brain more specifically. Since the overall task is openended, students have to learn how to analyze the current state of their model and find combinations of the different subtasks that help them make progress toward teaching Betty the correct science model. In other words, students must develop and apply metacognitive strategies for setting goals, developing plans for achieving these goals, monitoring their plans as they execute them, and evaluating their progress toward their goals in ways that can help them make decisions on whether to continue, refine, and change their approach so they can continue to make progress.

The task model (Fig. 2) defines three broad classes of OELE tasks related to: (i) information seeking and acquisition, (ii) solution construction and refinement, and (iii) solution assessment. Each of these task categories is further broken down into three levels that represent: (i) general task descriptions that are common across many OELEs; (ii) Betty's Brain specific instantiations of these tasks; and (iii) interface features in Betty's Brain that help students accomplish these tasks. The directed links in the task model represent dependency relations. Information seeking and acquisition depends on one's ability to identify, evaluate the relevance of, and interpret information. In the Betty's Brain system, primary information about the domain is provided in the form of hypertext resources. Feedback provided by the mentor and Betty provides students with additional information on how they can improve Betty's current map. Solution construction and refinement tasks depend on one's ability to apply information gained from both the information seeking tools and the solution assessment results to constructing and refining the solution in progress. In the Betty's Brain system, this translates to building and refining the causal map structure. Finally, solution assessment tasks depend on one's ability to interpret the results of solution assessments as actionable information that can be used to refine the solution in progress. This involves asking Betty to take quizzes and trying to interpret why certain questions were answered correctly and others were not. In order to accomplish these tasks in Betty's Brain, students must understand how to perform the related Betty's Brain specific tasks by utilizing the system's interface features.

The structure of the task model makes it easy to see why a number of students struggled to succeed in teaching Betty. To be successful, students must learn to perform a diverse set of tasks. Some students may fail because, while they are good readers, they are unfamiliar with (and, therefore, unable to grasp) the causal modeling language and reasoning mechanisms. Others may fail because they do not understand how to use Betty's quiz results to determine what links in their map are correct and incorrect. To truly help students succeed, we need to develop accessible scaffolds that are targeted toward supporting students' development of these skills. The idea, derived from the

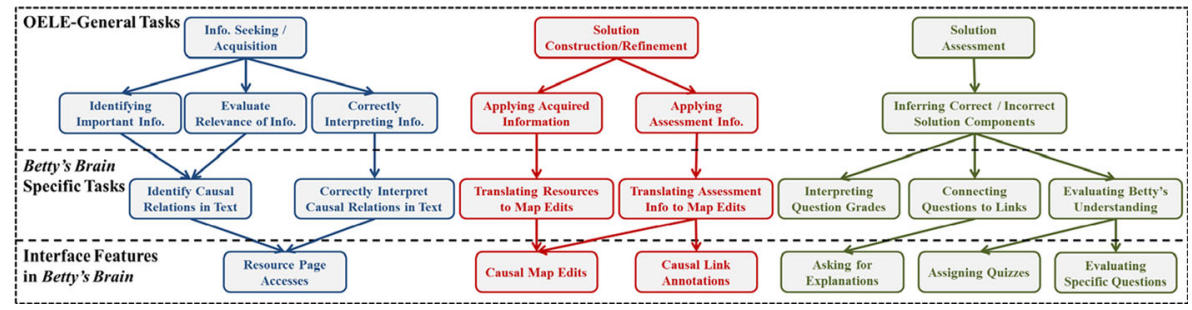

Fig. 2 Task model for OELEs 
learning sciences literature, implies that students will be more receptive to learning a new skill when they realize its importance in successfully completing a task, and learning the skill in context will help them operationalize it more effectively (Bransford et al. 1990; Bransford et al. 2000; Cobb and Bowers 1999; Lave and Wenger 1991). To do this, we redesigned the Betty's Brain interface, and simultaneously began creating new scaffolding functions for Betty and Mr. Davis.

Figure 3 presents the new Betty's Brain interface. Like its predecessor, this new system allows students to read about a science topic, teach it to Betty, and ask her to answer questions and take quizzes. However, the interfaces for acquiring information, constructing the causal map, and testing the map by having Betty take quizzes have been redesigned so that at any time when the student is interacting with the system, only one of these interfaces is visible. This allows the program to determine more precisely what the student is focusing on at any time and track shifts between reading, teaching, and quizzing. In addition, the system includes several new tools for students to use while learning and teaching. The quiz interface, for example, allows students to click on a quiz question and immediately see the links that Betty used to generate her answer. This makes it easier for students to determine the set of links used in correct and incorrect answers on the quiz. When Betty's answer to a quiz question is correct, all of the links used to answer the question are correct. Thus, this interface allows students to quickly view the set of links used to correctly answer a question. This, in turn, makes it easier for students to pay attention to incorrect links or links that may be missing from the causal map.

The ability to track how students shift between resource pages, the causal map, and quizzes has additional advantages. It has allowed us to develop a new and more powerful approach to analyzing students' problem solving processes. This approach, called coherence analysis (CA; Segedy et al. 2015), analyzes learner behaviors by combining information gleaned from sequences of student actions to produce measures of action coherence. Using these measures, we can characterize students' problem-

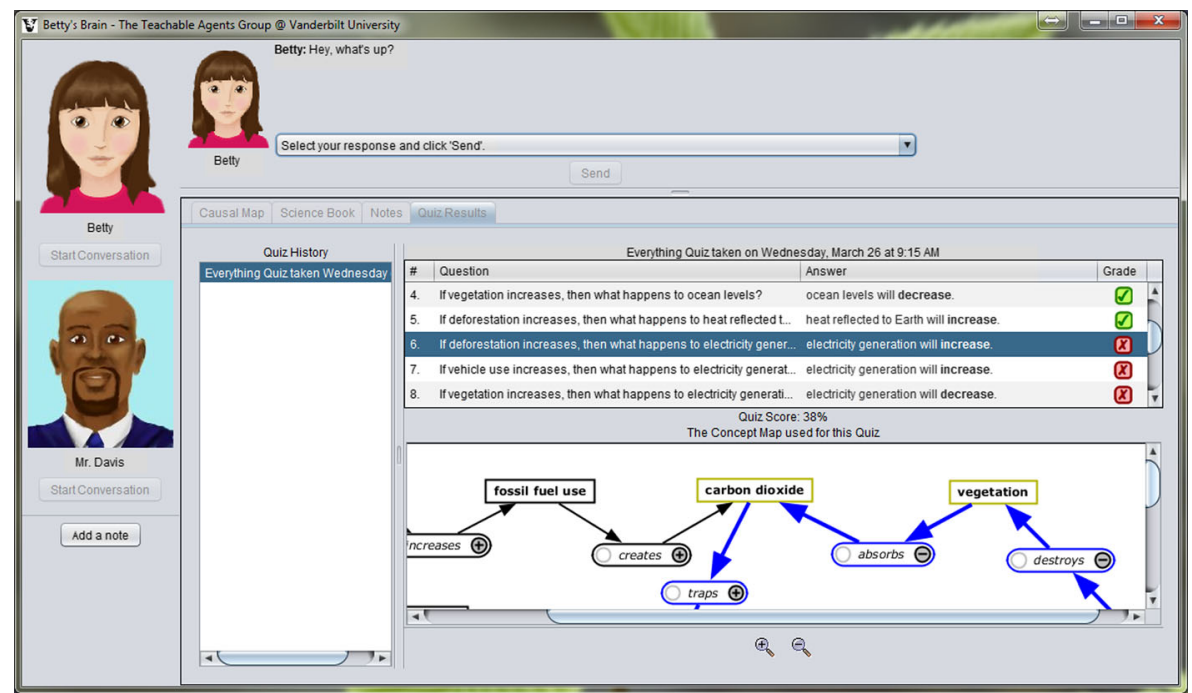

Fig. 3 New Betty's Brain showing the quiz interface 
solving approaches in ways that help us better understand students' capabilities, and, therefore, make more informed scaffolding decisions than in the previous versions of our learning environment.

CA focuses on how students interpret and apply the information they encounter while working in an OELE such as Betty's Brain. When students take actions that put them into contact with information that can help them improve their current solution (e.g., by reading about a causal relation), they have generated potential that should motivate and support future actions (e.g., teaching Betty that causal relation). The assumption is that if students can recognize relevant information in the resources and quiz results, then they should act on that information. If they do not, CA assumes that they did not recognize or understand the relevance of the information. This may stem from incomplete or incorrect domain knowledge (i.e., science) understanding, task understanding, and/or metacognitive knowledge. In addition, when students edit their map without encountering any information that justifies that edit, CA labels this as an unsupported edit and assumes that they are guessing ${ }^{1}$.

In more detail, we have derived measures from students' activity traces within our CA framework. For illustration purposes, we list them below:

1. Edits/Annotations per Minute: The number of causal link edits and annotations made by the student divided by number of minutes that the student was logged onto the system.

2. Unsupported edit percentage: the percentage of causal link edits and annotations not supported by any of the previous views (of the resources and quiz results) occurring within a five minute window of the edit.

3. Information viewing time: the amount of time spent viewing either the science resource pages or Betty's quizzes. Information viewing percentage is the percentage of the student's time on the system classified as information viewing time.

4. Potential generation time: the amount of information viewing time spent viewing information that could support causal map edits that would improve the map score. Potential generation percentage is the percentage of information viewing time classified as potential generation time.

5. Used potential time: the amount of potential generation time associated with views that occur within a prior five minute window and support an ensuing causal map edit. Used potential percentage is the percentage of potential generation time classified as used potential time.

6. Disengaged time: the sum of all periods of time, at least five minutes long, during which the student neither: (1) viewed a source of information (i.e., the science resources or Betty's quiz results) for at least $30 \mathrm{~s}$; nor (ii) added, changed, deleted, or annotated concepts or links. This metric represents periods of time during which the learner is not measurably engaged with the system. Disengaged percentage is the percentage of the student's time on the system classified as disengaged time.

\footnotetext{
${ }^{1}$ In reality, students may be applying their prior knowledge. However, the assumption is that since students are typically novices in the domain that they are studying, they should verify their prior knowledge before teaching it to Betty.
} 
Metrics one and two capture the quantity and quality of a student's causal link edits and annotations, where supported edits and annotations are considered to be of higher quality. Metrics three, four, and five capture the quantity and quality of the student's time viewing either the resources or Betty's graded answers. These metrics speak to the student's ability to identify resource pages that may help them build or refine their map (potential generation percentage) and then utilize information from those pages in future map editing activities (used potential percentage). In these analyses, a page view generated potential and supported edits only if it lasted at least $10 \mathrm{~s}$. Similarly, students had to view quiz results for at least $2 \mathrm{~s}$. These cut-offs helped filter out irrelevant actions (e.g., rapidly flipping through the resource pages without reading them).

By characterizing behaviors in this manner, CA provides insight into students' openended problem-solving strategies as well as the extent to which they understand the nuances of the learning task they are currently working on. Results of applying CA to data from a recent classroom study with Betty's Brain (Segedy et al. 2015) showed: (i) CA-derived metrics predicted students' task performance and learning gains; (ii) CAderived metrics correlated significantly with students' prior skill levels, demonstrating a link between task understanding and effective open-ended problem solving behaviors; and (iii) clustering students based on their CA-derived metrics identified common problem-solving approaches among students in the study.

Table 1 below includes results of clustering students according to the six measures of action coherence listed above while using Betty's Brain (see Segedy et al. 2015; Segedy 2014 for details of the analysis).

The clustering analysis revealed 5 distinct behavior profiles among the 98 students in the study. Cluster 1 students $(n=24)$ may be characterized as frequent researchers and careful editors; these students spent large proportions of their time $(42.4 \%)$ viewing sources of information and did not edit their maps very often. When they did edit the map, the edit was usually supported by recent activities (unsupported edit percentage $=29.4 \%$ ). Most of the information they viewed was useful for improving their causal maps (potential generation percentage $=71.4 \%$ ), but they often did not take advantage of this information (used potential percentage $=58.9 \%$ ). Cluster 2 students $(n=39)$ may be characterized as strategic experimenters. These students spent a fair proportion of their time $(33.5 \%)$ viewing sources of information, and, like Cluster 1

Table 1 Means (and standard deviations) of coherence measures, broken down by cluster

\begin{tabular}{lllllll}
\hline Cluster & $\begin{array}{l}\text { Edits }+ \\
\text { Annotations/ } \\
\text { min }\end{array}$ & Unsup. Edit $\%$ & Info. View \% & $\begin{array}{l}\text { Potential } \\
\text { Gen. } \%\end{array}$ & Used Potential \% & Disengaged \% \\
\hline $\begin{array}{l}\text { 1. Res./Careful } \\
\text { Editors }(n=24)\end{array}$ & $0.30(0.11)$ & $29.4 \%(16.1 \%)$ & $42.4 \%(11.0 \%)$ & $71.4 \%(10.6 \%)$ & $58.9 \%(15.4 \%)$ & $15.7 \%(9.9 \%)$ \\
$\begin{array}{l}\text { 2. Str. Exps. } \\
(n=39)\end{array}$ & $0.60(0.23)$ & $54.4 \%(14.8 \%)$ & $33.5 \%(8.3 \%)$ & $58.7 \%(18.9 \%)$ & $62.6 \%(16.2 \%)$ & $10.9 \%(7.4 \%)$ \\
$\begin{array}{l}\text { 3. Confused } \\
\text { Guessers }(n=5)\end{array}$ & $0.21(0.06)$ & $73.5 \%(13.5 \%)$ & $58.9 \%(7.7 \%)$ & $45.8 \%(19.4 \%)$ & $23.1 \%(12.6 \%)$ & $4.8 \%(5.4 \%)$ \\
$\begin{array}{c}\text { 4. Disengaged } \\
(n=6)\end{array}$ & $0.33(0.11)$ & $74.7 \%(17.4 \%)$ & $27.0 \%(9.6 \%)$ & $54.9 \%(9.3 \%)$ & $28.0 \%(8.7 \%)$ & $33.6 \%(8.4 \%)$ \\
$\begin{array}{c}\text { 5. Engaged/ } \\
\text { Efficient }(n=24)\end{array}$ & $1.04(0.32)$ & $29.1 \%(15.2 \%)$ & $35.4 \%(8.6 \%)$ & $76.8 \%(9.5 \%)$ & $82.0 \%(9.0 \%)$ & $3.1 \%(5.0 \%)$
\end{tabular}


students, often did not take advantage of this information (used potential percentage $=$ $62.6 \%$ ). Unlike Cluster 1 students, they performed several more map edits, a higher proportion of which were unsupported, as they tried to discover the correct causal model.

Cluster 3 students $(n=5)$ may be characterized as confused guessers. These students edited their maps fairly infrequently and usually without support. They spent an average of $58.9 \%$ of their time viewing sources of information, but most of their time viewing information did not generate potential (potential generation percentage $=$ $45.8 \%$ ). One possibility is that these students struggled to differentiate between more and less helpful sources of information. Unfortunately, when they did view useful information, they often did not take advantage of it (used potential percentage $=$ $23.1 \%$ ), indicating that they may have struggled to understand the relevance of the information they encountered. Students in Cluster $4(n=6)$ may be characterized as disengaged from the task. On average, these students spent more than $30 \%$ of their time on the system (more than 45 min of class time) in a state of disengagement. Like confused guessers, disengaged students had a very high proportion of unsupported edits, low potential generation percentage, and low used potential percentage. In addition, their information viewing percentage was much lower, though their edits per minute were slightly higher than the confused guessers.

Cluster 5 students $(n=24)$ are characterized by high levels of editing and annotating links (just over 1 edit per minute), and most of these students' edits (70.9\%) were supported. Additionally, they spent just over one third of their time viewing information, and over three fourths of this time was spent viewing information that generated potential. These students are distinct from students in the other four clusters in that they used a large majority of the potential they generated $(82.0 \%)$ and were rarely in a state of disengagement $(3.1 \%)$. In other words, these students appeared to be engaged and efficient. Their behavior is indicative of students who knew how to succeed in Betty's Brain and were willing to exert the necessary effort.

In comparing the learning and performance of students in these clusters (for additional details on these comparisons, see Segedy et al. 2015; Segedy 2014), we found that Cluster 5 students, who were characterized as engaged and efficient, had higher reading scores on skill tests and exhibited significantly higher science gains when compared to all other clusters. In contrast, Cluster 3 students, who were characterized as confused guessers, had significantly lower skill scores on both the pre-test and post-test when compared to most other clusters. However, this disadvantage did not measurably prevent them from learning the science content; their learning gains were not significantly different from the learning gains achieved by students in Clusters 1, 2, and 4. Additionally, strategic guessers achieved higher map scores than both the disengaged students and confused guessers. Frequent researchers and careful editors also achieved higher map scores than disengaged students. As with the learning results, engaged and efficient students performed significantly better than all other groups of students.

\section{Reflections and Future Directions}

Throughout the course of our research with Betty's Brain, the goal has always been to help students become effective and independent science learners. To achieve this, we 
have developed a computer-based learning environment that is learner-centered and open-ended, allowing students to direct their own learning processes. In particular, we have focused on learning science by building and reasoning with models. As our research with the Betty's Brain system has progressed, we have come to understand that using virtual agents assigned specific supportive roles (e.g., student, mentor) can engage and motivate students. But some students still face difficulties in combining learning, building, and checking tasks when attempting to build and reason with their science models. By developing coherence analysis (CA), our ability to understand the specific difficulties individual students face has increased significantly, and our focus has shifted to detecting students who struggle to succeed as they work in Betty's Brain and providing them with relevant scaffolds to help them overcome their difficulties.

We now have a framework for characterizing the tasks students need to complete to be successful in teaching Betty (Fig. 2 - the hierarchical task model) and a method for interpreting students' problem-solving behaviors as they work in the Betty's Brain environment. These greatly increase our ability to adapt to students as they use our system. We have started experimenting with scaffolding students who exhibit poor coherence. Thus far, we have focused on teaching students how to accomplish the tasks in the task model through guided skill practice (Segedy et al. 2013a, b). In the future, we will look to develop and test additional scaffolds that focus more on metacognitive strategies for solving complex, open-ended problems.

An important result from our recent work in OELEs in general, and Betty's Brain in particular, has been in developing the CA framework with supporting analytic measures. We have found that CA, as separate from students' learning and performance, provides insight into aspects of students' problem solving behaviors, particularly in OELEs. Several of the behavior profiles that we identified using cluster analysis exhibited similar levels of prior knowledge, prior skill levels, success in teaching Betty, and learning while using the system. CA helps us understand how different behaviors can result in the same level of performance and learning. In fact, one of the more interesting findings that emerged from the above-referenced study is that CA-derived metrics were able to distinguish groups of students with distinct behavior profiles beyond what was possible when only focusing on learning gains and the correctness of students' causal maps. Given this, one potentially valuable application of CA in OELEs is presenting CA-derived metrics to classroom teachers for evaluation and formative assessment. Ideally, teachers could use these reports to quickly and easily: (i) understand learners' problem-solving approaches; (ii) infer potential reasons for the levels of success achieved by students; and (iii) make predictions about students' learning and task understanding. Moreover, teachers could use these reports to assign performance and effort grades and implement classroom and homework activities that target the aspects of SRL and problem solving that students are struggling with. We plan to investigate this further in our future research.

In the future, we will extend our scaffolding approach to provide the right combination of meta-cognitive strategy and task-specific skill feedback through our virtual agents in the Betty's Brain system. We are currently working on using results from our work in sequence mining of students' activity sequences (Kinnebrew et al. 2013) to track and interpret students' strategy use as they work in the environment. Combining the sequence mining results with CA will provide a powerful framework for understanding students' learning behaviors in the more expansive framework of strategy use, 
task skills, and learning performance (i.e., the ability to make progress toward building correct science models). This framework will help to better contextualize the feedback provided to students, and help students become more self-directed and independent learners.

In addition, we will explore how students' CA metrics change over time to understand how students adapt their approaches as they use the system. We will investigate what leads to these changes, and, depending on the change, how to encourage or prevent these changes. We may be able to identify "at risk" behavior profiles and take action to prevent students from disengaging from the task. Additional work will investigate how these changes relate to students' affective states. We are currently investigating methods for incorporating affect detectors into Betty's Brain to investigate how affect influences open-ended problem solving.

Last, one of our additional goals is to help students understand the importance and role of scientific modeling in problem solving, especially when the problems connect the science models to the real world (scenarios). For example, we have run preliminary studies where 6th grade students, after they have successfully taught Betty a model that captures the impact of certain human activities on climate change, work together to identify scenarios in their school or their neighborhoods where the carbon footprint is high, and then propose solutions that will help reduce the carbon footprint. Other examples include designing self-sustaining eco-columns for fish, plants, and other living organisms, based on lessons learned from constructing a causal model of ecological processes in a pond ecosystem. This larger focus will also enable us to extend our learning environment to support and study collaborative problem solving (Barron 2000; Palincsar et al. 1993), and develop assessments that support preparation for future learning (Bransford and Schwartz 1999).

\section{References}

Adams, E. (2010). Fundamentals of game design (2nd ed.). Berkeley: New Riders Pub.

Arias, E., Eden, H., Fischer, G., Gorman, A., \& Scharff, E. (2000). Transcending the individual human mind-creating shared understanding through collaborative design. ACM Transactions on ComputerHuman Interaction (TOCHI), 7(1), 84-113.

Bargh, J. A., \& Schul, Y. (1980). On the cognitive benefits of teaching. Journal of Educational Psychology, 72(5), 593-604.

Barron, B. (2000). Achieving coordination in collaborative problem-solving groups. The Journal of the Learning Sciences, 9(4), 403-436.

Benware, C. A., \& Deci, E. L. (1984). Quality of learning with an active versus passive motivational set. American Educational Research Journal, 21(4), 755-765.

Biswas, G., Schwartz, D., \& Bransford, J. (2001). Technology support for complex problem solving: From SAD environments to AI. In K. D. Forbus \& P. J. Feltovich (Eds.), Smart machines in education (pp. 7198). Menlo Park: AAAI Press.

Biswas, G., Leelawong, K., Belynne, K., \& Adebiyi, B. (2005). Case studies in learning by teaching behavioral differences in directed versus guided learning. In: Proceedings of the 27th Annual Conference of the Cognitive Science Society (pp. 828-833). Stresa, Italy.

Biswas, G., Leelawong, K., Schwartz, D., \& Vye, N. (2005b). Learning by teaching: a new agent paradigm for educational software. Applied Artificial Intelligence, 19(3-4), 363-392.

Biswas, G., Jeong, H., Kinnebrew, J., Sulcer, B., \& Roscoe, R. (2010). Measuring self-regulated learning skills through social interactions in a teachable agent environment. Research and Practice in Technology Enhanced Learning, 5(2), 123-152. 
Bransford, J., \& Schwartz, D. (1999). Rethinking transfer: a simple proposal with multiple implications. Review of Research in Education, 24(1), 61-101.

Bransford, J. D., Sherwood, R. D., Hasselbring, T. S., Kinzer, C. K., \& Williams, S. M. (1990). Anchored instruction: Why we need it and how technology can help. In D. Nix \& R. J. Spiro (Eds.), Cognition, education, and multimedia: exploring ideas in high technology (pp. 115-141). Hillsdale: L. Erlbaum.

Bransford, J., Brown, A., \& Cocking, R. (Eds.). (2000). How People Learn. Washington, D.C.: National Academy Press.

Brophy, S., Biswas, G., Katzlberger, T., Bransford, J., \& Schwartz, D. (1999). Teachable agents: Combining insights from learning theory and computer science. In S. P. Lajoie \& M. Vivet (Eds.), Artificial intelligence in education (pp. 21-28). Amsterdam: IOS Press.

Chan, T. W., \& Chou, C. Y. (1997). Exploring the design of computer supports for reciprocal tutoring. International Journal of Artificial Intelligence in Education, 8, 1-29.

Chase, C. C., Chin, D. B., Oppezzo, M. A., \& Schwartz, D. L. (2009). Teachable agents and the protégé effect: increasing the effort towards learning. Journal of Science Education and Technology, 18(4), 334-352.

Clarebout, G., \& Elen, J. (2008). Advice on tool use in open learning environments. Journal of Educational Multimedia and Hypermedia, 17(1), 81-97.

Cobb, P., \& Bowers, J. (1999). Cognitive and situated learning perspectives in theory and practice. Educational Researcher, 28(2), 4-15.

Cohen, P., Kulik, J., \& Kulik, C. (1982). Educational outcomes of tutoring: a meta-analysis of findings. American Educational Research Journal, 19(2), 237-248.

Dillenbourg, P. (1999). What do you mean by collaborative learning? Collaborative-learning: Cognitive and Computational Approaches (pp. 1-19). Oxford: Elsevier.

Goos, M. (1994). Metacognitive decision making and social interactions during paired problem solving. Mathematics Education Research Journal, 6, 144-165.

Kinnebrew, J. \& Biswas, G. (2012). Identifying learning behaviors by contextualizing differential sequence mining with action features and performance evolution. In: K. Yacef, O. Zaîane, H. Hershkovitz, M. Yudelson, \& J. Stamper (Eds.) Proceedings of the 5th International Conference on Educational Data Mining (pp. 57-64). International Educational Data Mining Society.

Kinnebrew, J., Loretz, K., \& Biswas, G. (2013). A contextualized, differential sequence mining method to derive students' learning behavior patterns. Journal of Educational Data Mining, 5(1), 190-219.

Kinnebrew, J. S., Segedy, J. R., \& Biswas, G. (2014). Analyzing the temporal evolution of students' behavior in open-ended learning environments. Metacognition and Learning, 9(2), 187-215.

Land, S. (2000). Cognitive requirements for learning with open-ended learning environments. Educational Technology Research and Development, 48(3), 61-78.

Land, S., Hannafin, M., \& Oliver, K. (2012). Student-centered learning environments: Foundations, assumptions and design. In D. Jonassen \& S. Land (Eds.), Theoretical foundations of learning environments (pp. 3-25). New York: Routledge.

Lave, J., \& Wenger, E. (1991). Situated learning: Legitimate peripheral participation. Cambridge: Cambridge University Press.

Leelawong, K., \& Biswas, G. (2008). Designing learning by teaching agents: The Betty's Brain system. International Journal of Artificial Intelligence in Education, 18(3), 181-208.

Michie, D., Paterson, A., \& Hayes-Michie, J. (1989). Learning by Teaching. In: 2nd Scandinavian Conference on Artificial Intelligence 89 (pp. 307-331). Amsterdam: IOS Press.

Obayashi, F., Shimoda, H., \& Yoshikawa, H. (2000). Construction and evaluation of CAI system based on learning by teaching to virtual student. World Multiconference on Systemics, Cybernetics and Informatics (pp. 94-99). Volume 3. Orlando, Florida.

Palincsar, A. S. (1998). Social constructivist perspectives on teaching and learning. Annual Review of Psychology, 49, 345-375.

Palincsar, A. S., \& Brown, A. L. (1984). Reciprocal teaching of comprehension-fostering and comprehensionmonitoring activities. Cognition and Instruction, 1, 117-175.

Palincsar, A. S., Anderson, C., \& David, Y. M. (1993). Pursuing scientific literacy in the middle grades through collaborative problem solving. The Elementary School Journal, 93(5), 643-658.

Palthepu, S., Greer, J., \& McCalla, G. (1991). Learning by teaching. In The Proceedings of the International Conference on the Learning Sciences (pp. 357-363). Charlottesville, VA: Association for the Advancement of Computing in Education.

Roscoe, R., \& Chi, M. (2007). Understanding tutor learning: knowledge-building and knowledge-telling in peer tutors' explanations and questions. Review of Educational Research, 77(4), 534-574.

Scardamalia, M., \& Bereiter, C. (1989). Conceptions of teaching and approaches to core problems. In M. C. Reynolds (Ed.), Knowledge base for the beginning teacher (pp. 37-46). New York: Pergamon Press. 
Schwartz, D. L., Blair, K. P., Biswas, G., Leelawong, K., \& Davis, J. (2007). Animations of thought: Interactivity in the teachable agent paradigm. In R. Lowe \& W. Schnotz (Eds.), Learning with animation: Research and implications for design (pp. 114-140). UK: Cambrige University Press.

Segedy, J. R. (2014). Adaptive scaffolds in open-ended computer-based learning environments (Doctoral dissertation). Nashville: Department of EECS, Vanderbilt University.

Segedy, J.R., Kinnebrew, J., \& Biswas, G. (2012a). Relating student performance to action out-comes and context in a choice-rich learning environment. In: S. Cerri, W. Clancey, G. Papadourakis, \& L. Panourgia (Eds.), Intelligent Tutoring Systems: Vol. 7315. Lecture Notes in Computer Science (pp. 505-510). Springer.

Segedy, J.R., Kinnebrew, J., and Biswas, G. (2012b). Supporting student learning using conversational agents in a teachable agent environment. In J. van Aalst, K. Thompson, M. Jacobson, \& P. Reimann (Eds.), The future of learning: Proceedings of the 10th international conference of the learning sciences (ICLS 2012): Vol. 2. Short Papers, Symposia, and Abstracts (pp. 251-255). International Society of the Learning Sciences.

Segedy, J.R., Biswas, G., Blackstock, E., \& Jenkins, A. (2013a). Guided skill practice as an adaptive scaffolding strategy in open-ended learning environments. In: H.C. Lane, K. Yacef, J. Mostow, \& P. Pavlik, (Eds.), Artificial Intelligence in Education: Vol. 7926. Lecture Notes in Computer Science (pp. 532-541). Springer.

Segedy, J. R., Kinnebrew, J., \& Biswas, G. (2013b). The effect of contextualized conversational feedback in a complex open-ended learning environment. Educational Technology Research and Development, 61(1), 71-89.

Segedy, J. R., Biswas, G., \& Sulcer, B. (2014). A model-based behavior analysis approach for open-ended environments. Journal of Educational Technology \& Society, 17(1), 272-282.

Segedy, J.R., Kinnebrew, J.S., \& Biswas, G. (2015). Using coherence analysis to characterize self-regulated learning behaviours in open-ended learning environments. Journal of Learning Analytics, 2(1), in press.

Tan, J., \& Biswas, G. (2006). The role of feedback in preparation for future learning: A case study in learning by teaching environments. In Intelligent Tutoring Systems: Vol. 4053. Lecture Notes in Computer Science (pp. 370-381). Springer.

Tan, J., Biswas, G., \& Schwartz, D. (2006). Feedback for metacognitive support in learning by teaching environments. In Proceedings of the 28th Annual Meeting of the Cognitive Science Society (pp. 828833). Vancouver, Canada.

Vygotsky, L. (1978). Mind in society: The development of higher psychological processes. Cambridge: Harvard University Press.

Wagster, J., Tan, J., Biswas, G., \& Schwartz, D. (2007). Do learning by teaching environments with metacognitive support help students develop better learning behaviors? In: D. McNamara \& J. Trafton (Eds.) Proceedings of the 29th Annual Meeting of the Cognitive Science Society (pp. 695-700). Austin, TX: Cognitive Science Society.

Wagster, J., Kwong, H., Segedy, J., Biswas, G., \& Schwartz, D. (2008). Bringing CBLEs into classrooms: Experiences with the Betty's Brain system. In Proceedings of the Eighth IEEE International Conference on Advanced Learning Technologies (pp. 252-256). Santander, Cantabria, Spain.

Willis, J., \& Crowder, J. (1974). Does tutoring enhance the tutor's academic learning? Psychology in the Schools, 11, 68-70. 